\title{
Interpretivist Entrepreneurial Research on Indian Millennial: An R/R-QDA Based Approach
}

\author{
Surjit Kumar Kar'1, Saroj Kanta Biswal ${ }^{2}$ \\ ${ }^{1}$ Department of Marketing \& Strategy, IBS Hyderabad (A Constituent of the ICFAI Foundation for Higher Education), Hyderabad, India \\ ${ }^{2}$ Faculty of Management Sciences, Siksha 'O' Anusandhan, Bhubaneswar, India \\ Email: surjitk@ibsindia.org, sarojkantabiswal@soa.ac.in
}

How to cite this paper: Kar, S.K. and Biswal, S.K. (2019) Interpretivist Entrepreneurial Research on Indian Millennial: An R/R-QDA Based Approach. Theoretical Economics Letters, 9, 2198-2216. https://doi.org/10.4236/tel.2019.96139

Received: July 8, 2019

Accepted: August 27, 2019

Published: August 30, 2019

Copyright () 2019 by author(s) and Scientific Research Publishing Inc. This work is licensed under the Creative Commons Attribution International License (CC BY 4.0).

http://creativecommons.org/licenses/by/4.0/

(c) (i) Open Access

\begin{abstract}
Research on entrepreneurship domain and its different dimensions is not new. This paper explores entrepreneurial orientation of Indian millennial and their motivations using open source R/RQDA packages through a qualitative paradigm. The sociological method called "interpretivism" uses qualitative approach which is humanistic as opposed to scientific methods followed by "positivism". This study uses qualitative data generation techniques e.g. participant observation, focus group discussion, and unstructured interviews, with an emphatic understanding of individual accounts. It applies thematic coding and categorization of the participants' narratives on a computer assisted platform for grounding it into a theoretical model. Individuals in Indian millennial cohort, don't just positively react to external positive stimuli to pursue an entrepreneurial career, they possess values e.g. altruism and societal orientation. Narratives from individual accounts manifest different perspectives on singular objective reality as would be broadly construed as social constructionism of Indian milieu. The computing environment of R/RQDA (Source: CRAN) for data coding, aggregation, plotting and theorization on personal narratives drawn from limited accounts in a group setting asserts on the findings that are most appropriate in recent cultural shift witnessing India such as unleashing individual potential or cooperative capitalism toward social change. Identifying a group of budding entrepreneurs currently pursuing business management program and looking for a near future objective realization of an entrepreneurial career was a part of the sampling. Data triangulation is a natural improvement for generalization of the findings to make it a more relevant outcome, and is a limitation of the current study.
\end{abstract}

\section{Keywords}

Interpretivism, Social Constructionism, Entrepreneurship, Millennial 


\section{Introduction}

Sociological research has various approaches and methods, some with scientific orientation and some with humanistic exploration. There are various computer assisted software packages to carry out such research with greater impact towards retrieval and visualization of outcome. Qualitative research delves on the premise of non-numerical/non-quantifiable data that can only be interpreted in some given context. The theory of social constructionism accepts that reality is socially constructed, and focuses on the constructive force of language to be used as a strategy of analysis. In post-modern era, social constructionism has emerged as one of the most influential paradigm, however it often invites criticism as it denies existence of a physical reality. Interpretivism assumes that the given or socially constructed reality is through social constructions e.g. language, consciousness, shared meanings, and instruments [1]. Interpretivism rests on two premises: Relativist ontology (reality is perceived inter-subjectively) and Transactional or subjectivist epistemology (Inseparability of the interlinkages between researcher and research subject). Pizam and Mansfeld [2] have differentiated tenets of interpretivism from that of positivism as:

- Nature of reality: socially constructed \& multiple.

- Goal of research: understanding, weak prediction.

- Focus of interest: what is specific, unique and deviant.

- Knowledge generated: Meanings relative (time, context, culture, value, and bound).

- Subject/Researcher relationship: Interactive, cooperative, participative.

- Desired information: what some people think \& do, what problems they confront with, \& how they deal.

In research on the phenomenon of "entrepreneurship" it is often favorably argued to use social constructionism theory of social reality. Social constructionist approach follows two streams of analyses, e.g. 1) foucauldian discourse analysis (named after Michel Foucault-it is a type of discourse analysis that is centered on power relationships expressed through language and practices in society) and 2) deconstruction (As posited by J. Derrida-it is an approach to understand the relationship between text and meaning). The current study uses Interpretivist study over the premise of relativist ontology and explores socially constructed reality of entrepreneurship by Indian millennial cohort expressed through language and practices in the society represented by a group of budding entrepreneurs.

Entrepreneurship: Bolton and Thompson [3] [4] define entrepreneurs as people who habitually create and innovate to build something of recognized value around perceived opportunities. Business techniques matter but don't define the entrepreneur, rather relative strength of certain natural characteristics or character themes exist. Various characteristics of an entrepreneur are seen being instrumental in making a venture successful It may include vision and focus of the individual, intensity and length of engagement time, target selection and ac- 
tion, benefit and performance orientation, resourcing capability, creative skills, ideas and opportunity generation, problem solving spirit and ability, ego, esteem and motivational drive, personal dedication, responsibility and accountability and so on and so forth. Many of these traits manifest in an individual over a period of time being gradually shaped and seasoned in the trade. Different skills and abilities may be needed to carry out different types of ventures.

Gurol and Atsan [5] observed that entrepreneurship can provide a major source of employment creation, innovation and social adjustment for a developing economy. This applies in the context of India. With increase in youth percentage in population, India is becoming younger, experimental and aspirational. It can be seen both as opportunity as well as challenge for planning and development agencies. Start-up funding comes up an issue to foster growth of entrepreneurship in aspiring youth. The field being open and inviting for many, personal and professional skills and competencies become an integral area of concern too. Thus, along with funding, something that becomes equally important is mentoring. Hence, funding agencies prefer to offer or organize mentoring support either through from a mentoring perspective or from a financial perspective [6]. Business incubators are companies that provide services e.g. management training or office space to new and start-up companies and work as catalyst for either regional or national economic development (The National Business Incubation Association). There are various types of funding and support agencies operating at different levels of expertise in the entrepreneurial ecosystem of an emerging economy like India.

Indian Scenario: Government of India (GoI) has been creating supportive ecosystem to inculcate an entrepreneurial mind set in students graduating from general, vocational, technology or management schools. Startups in India are coming up in almost every category of business e.g. lifestyle, digital, social etc. Many new trends are being noticed in India. Family businesses are being scaled up by incumbent new generations in the family [7]. Scalable startups are being created which can be sold \& flipped at will. Large companies are initiating idea contests, startup funding, and investment. Social entrepreneurship and technology based startups are at new heights. Many people come to this domain with many different types of motivation and commitment. Some could be serial entrepreneur, whereas some could be emerging social entrepreneur, and yet some other could be visionary thought leader looking for permanent solutions to perennial problems. Startup India is a flagship initiative of the Government of India, intended to build a strong eco-system for nurturing innovation and startups in the country. Startup India Portal is a facilitation platform for Startup recognition, access to information on incubators, mentors, Angel Funds, Venture Funds etc. On completion of seven years from the date of its incorporation/registration or at the end of the financial year in which its turnover exceeds INR 25 crore, an entity ceases to be Startup (ten years for startups in biotechnology sector). To accelerate spreading of the Startup movement in India, action plan of GoI is 
based on three pillars: 1) Simplification and Handholding; 2) Funding Support and Incentives; and 3) Industry-Academia Partnership and Incubation.

\section{Entrepreneurship Research}

There is plenty of research already available in the body of knowledge relating to the phenomenon of entrepreneurship. The literature has diverse types of qualitative and quantitative research papers on this area of study. As per Fraboni and Saltstone [8], characteristics of entrepreneurs are based on personality, attitudes, biography, demography [9] [10] and behavior in the business world. Entrepreneurs usually have higher risk taking ability, higher need for achievement, internal locus of control, work involvement \& motivation, tolerance for ambiguity and type-A behavior. A scale by Smith [11] measures need for achievement, which is an individual's internalized need for personal achievement and fulfilment. Intrinsic work motivation is the extent to which a person wants to be involved in work and wants to perform well [12]. Tolerance for ambiguity reflects one's perception about ambiguous situation and managing it in a calm and sensible manner [13]. Risk-taking propensity is about taking risks under financial, career and family related emotional and psychological uncertainty [14] [15] [16]. Self-efficacy, self-confidence, innovativeness [5] etc. are some individual entrepreneurial traits. Cassidy and Lynn [17] find that need for achievement comprises of factors like status aspiration, competitiveness, excellence, acquisitiveness and mastery. Along with individual factors an entrepreneur encounters various types of social/situational factors, e.g. family background, stage of career, features of the macro environment. Social development model by Gibb and Ritchie [18] explains that entrepreneurs are shaped up wholly in relation to early life experience, whereas interactionist model by Winfield [19] highlights on environmental contexts like social upheaval and supportive social/economic culture as necessary conditions for the expression of personality. Contingent model [20] focuses on traits and behaviors of a successful entrepreneur and its dependence on key features of the environment surrounding him/her. Evidence and developmental model emerged from the western economies. Parental role model [21] [22] [23] suggest that individuals with self-employed parents are more likely to start entrepreneurial venture. Family support model [24] [25] highlights influence of social and financial support provided by the family. Fagenson [26] found gender differences to be much smaller than those created by business experience. Many researchers have found that young people (25 - 30 years) are most energetic and ready to take the risk. There are specific competences in successful entrepreneurs from number of developing countries like India, Malawi and Ecuador [27]. From a regulatory perspective, many countries have their own ways of regulating the entrepreneurial ventures. Some follow low regulation and some follow high support route [28]. Baporikar [29] in her study of the phenomenon of youth entrepreneurship in India narrates that although there exists good enthusiasm, limitations in areas such as skills, networks and financing can act as barriers. She [29] explains that policy with sufficient support 
should target resources on young people with the best chance of success. This study tries to understand the personality traits and its dependence on existing eco-system [20] in India with a focus on Indian millennial, and gender differences [26] in the motivation, if any.

\section{Qualitative Research \& R/R-QDA}

There are different logics and models for writing qualitative papers [30] [31] [32] [33]. This may often create ambiguity and suffer lack of consensus \& agreeability on interpretation and findings. Theory building and discovery research remains more relevant output of a qualitative research. On the other hand it can be used also for theory testing and refinement research. Interpretivism in qualitative research assumes social reality through social constructions e.g. language, consciousness, shared meanings, and instruments [34]. Positivism, on the complementary side views social reality as objective and verifiable [35] [36]. This suggests that the two can be combined to study social reality under critical realism [37] [38] [39].

The computing science of modern genre has made lot of progress even in the conduct of qualitative research. This has given rise to a trend in scholars of qualitative study field an opportunity to introduce newer perspective into the same set of problem in hand. Methodological reprise using computer assisted qualitative data analysis has helped not only in process and conduct improvement but also has given a new meaning to qualitative research paradigm. $\mathrm{R}$ is open-source statistical software from Comprehensive R Archive Network (CRAN) and can be used for qualitative data analysis using techniques like sentiment analysis, text mining etc. However, RQDA developed by Huang [40] is an integrated platform for both quantitative and qualitative data analysis.

\subsection{Research Objectives}

The current study uses Interpretivist approach over the premise of relativist ontology and explores socially constructed reality of entrepreneurship by Indian millennial cohort expressed through language and practices in the society. This study attempts to answer few research questions:

Q1. What does Indian Millennial think about "Entrepreneurship"?

Q2. Do young Indian males and females differ in their understanding of the same?

Q3. What do they perceive about the current state of affairs in this context in the country?

Q4. What are the underlying factors for their motivation to opt for entrepreneurial career?

\subsection{Methodology, Data \& Unit of Analysis}

The research questions basically pertain to explore the viewpoints of young Indian millennials in the context of opting for an entrepreneurial career vis-à-vis 
any other option. The research frame selected for this study was a management school in India with a diverse population of students coming from almost all states of the country. Qualitative research is mostly conducted on data gathered through interviews, documents and observations, discussions etc. As the interpretivist approach rests on the principle of subjective enquiry, narratives of individual account (participant in focus group discussion and personal interview) was taken as unit of analysis.

Data Collection: Over two phases of data collection, the male participants were subjected to a moderated focus group discussion and the female participants were taken through a personal depth interview almost in line with similar enquiry as was done in FGD for moderation in order to keep it uniform (See: Appendix 2 for questions used for moderating the FGD \& conducting the depth interview). However, the participants in both the phases were given an introduction about the topic/phenomenon to be discussed upon meeting during FGD/depth interview (see: Appendix 1 for an Introductory Note). This study believes that gender differences in entrepreneurship remain much smaller than those created by business experience [26]. However, a changing Indian society with a fresh view can draw valuable input. Narratives enquiry or research in qualitative paradigm is a powerful tool in sharing of knowledge having cognitive issues of memory, constructed memory, and perceived memory [41]. The participant observation technique and narrative enquiry method with an objective distance were used across two phases of data collection among males $(\mathrm{N}=9)$ through FDG and females $(N=7)$ through depth interviews separately. The narratives gathered from individual accounts of individuals in through interview, and the thematic codes and categories drawn from group discussion were used as unit of analysis.

\subsection{Research Procedure \& Limitations}

The sample characteristics (identity reserved, state of domicile presented as vehicle registration code in that state) is presented in Appendix 3. This shows the attribution details of all narrative accounts. Selection of the sample respondent/participant from a diverse campus was based on criteria of membership in an Entrepreneurship Club. This assures the participants to have a desirable amount of motivation. Methodological steps as would be relevant for qualitative study were followed in following sequence:

1) Data was gathered as field texts \& diary notes, audio clips, and audio-visual clips.

2) Data gathered as above was transcribed from speech/audio into system readable words/texts (Free web based tools used)-Two copies were created.

3) QDA software packages (R \& R-QDA) were prepared/installed on systems with necessary dependency files.

4a) For Text Mining/Sentiment Analysis/Word Cloud using R package:

- Aggregate Data of all accounts was used to create character vector \& then 
single object vectors

- Data was cleaned for punctuation, stop-words, numbers, white space

- Data was transformed into all lower case

- A corpus of words created for analysis

4b) For QDA using R-QDA package:

- The second copy of data file was used \& key data attributes were recorded

- Individual accounts (.txt files) were imported to RQDA platform

- Thematic Coding \& Categorization of themes $\left(1^{\text {st }} \& 2^{\text {nd }}\right.$ order $)$

- Codes \& Categories were plotted

5) Identifying thematic relationships.

Limitations: In qualitative study as per existing literature, sample size is an area of concern, and different researchers propose different ways to deal with it. However, such study being based on in-depth narrative account of individual participants, an interpretivist thematic analysis on few such accounts can give meaningful summarization. In this study, the sample size limitation is taken care in two ways, 1) keeping the respondent profile similar to avoid radically differing views, and 2) Increasing the depth of conversation with limited number of respondents, till saturation is arrived. The findings from the study conducted in one natural settings of a typical sampling frame may not help generalization of it across a generational cohort. Thematic coding without an inter coder (informal consensus was reached) agreeability is a limiting factor. Different data collection methods have been arguably engaged with respect to different gender groups.

\section{Interpretivist Analysis}

\subsection{Thematic Analysis}

This was thematic analysis of the individual accounts of participants which were imported into the package R-QDA as separate files under a single project. Going through each of these accounts, thematic coding \& categorization was done by method suggested by (Gibbs, 2007). Similar codes were grouped under unique category in a process called "categorization". Each category was given a relevant name. Average number of files associated with each code is shown in Table 1.

The words like "Entrepreneur", "India", "Venture" etc. were considered

Table 1. Code weights based on files associated.

\begin{tabular}{clc}
\hline \multirow{2}{*}{ Weightage } & \multicolumn{1}{c}{ Code } & $\begin{array}{c}\text { \% of Files } \\
\text { Associated }\end{array}$ \\
\hline \multirow{2}{*}{ High } & Entrepreneur*, Self-made, Idea & $17.95 \%$ \\
& Motivation, Start new venture, Giving back to Society & $15.38 \%$ \\
& Social Motivation, Risk Appetite, Market, Eco-System, Social & \\
Medium & Acceptance, Government, Solution, Branding & $6.25 \%$ \\
& Government support, Funding, Education, Infrastructure, & \\
& Competition, Innovation, Social problems, Encouragement, & $5.00 \%$ \\
& Other support, Graduation
\end{tabular}


redundant and not contributing to the textual analysis. Hence they are not considered for interpretation although their frequency has been quantified. "Self-made", "Idea" are words with which almost 18\% of the documents are seen to be associated. This means that a millennial assigns value to creative idea in order to start an entrepreneurial venture and is someone who considers himself/herself as a self-made person. "Motivation", "Giving back to society"; or combining "motivation to give back to society" stands as second most frequent terms as $15 \%$ of the documents are associated with these. The motivation of millennials to explore social sphere for business opportunity is noticed here.

Table 2(a) shows the length of characters associated with each thematic code. The more the length the more explanation is given by the participant on the theme. Existing "Limitation" at personal or system level is expressed with more focus than anything else. Similarly, "Strong Foundation" and "Family support" are seen to be ones with second most important codes. Family background and moral support from family for a millennial to venture into entrepreneurship is still expressed at length. "Social problems" \& "Revolutionary ideas" are codes with prominent expression and explanation. This can be understood in the context of India, as Indian millennials seek opportunities for entrepreneurship in social issues or many of them seem to be interested to bring out solutions to existing social problems. "Social entrepreneurship" with an altruist need is seen

Table 2. (a) Code weights based on files associated; (b) Code frequencies.

(a)

\begin{tabular}{cc}
\hline Average no. of Characters Associated with Each Code \\
\hline Limitations & 130.500000 \\
Strong Foundation & 69.000000 \\
Family Support & 45.750000 \\
Social Problems & 43.142857 \\
Revolutionary & 42.000000 \\
Consumer Mindset & 36.000000 \\
Opportunistic & 33.166667 \\
Competition & 31.000000 \\
Self-Made & 29.181818 \\
Infrastructure & 27.714286 \\
Giving Back to the Environment & 27.142857 \\
Overcome Problems & 27.000000 \\
Expanding & 27.000000 \\
Encouragement & 26.000000 \\
Ecosystem & 25.555556 \\
Branding & 25.400000 \\
Influence & 25.000000 \\
\hline
\end{tabular}


(b)

\begin{tabular}{|c|c|}
\hline \multicolumn{2}{|c|}{ Number of Codings for Each Code } \\
\hline Entrepreneur ${ }^{*}$ & 21 \\
\hline Idea & 19 \\
\hline India ${ }^{*}$ & 16 \\
\hline Start New Venture & 15 \\
\hline Giving Back to the Society & 13 \\
\hline Solution & 13 \\
\hline Motivation & 12 \\
\hline Self-Made & 11 \\
\hline Government & 10 \\
\hline Social Motivation & 10 \\
\hline Social Acceptance & 9 \\
\hline Eco-System & 9 \\
\hline Risk Appetite & 9 \\
\hline Funding & 8 \\
\hline Improve & 8 \\
\hline Opportunities & 8 \\
\hline Other Support & 8 \\
\hline Encouragement & 7 \\
\hline Giving Back to the Environment & 7 \\
\hline Government Support & 7 \\
\hline Infrastructure & 7 \\
\hline Social Problems & 7 \\
\hline Opportunistic & 6 \\
\hline Online Platform & 5 \\
\hline Branding & 5 \\
\hline Competition & 5 \\
\hline Education & 5 \\
\hline${ }^{\star}$ Redundant & \\
\hline
\end{tabular}

among Indian millennials. "Competition", "Consumer mindset", "Expansion" etc. come in subsequence.

Table 2(b) shows code frequencies. More is the frequency of a code in the corpus, more is its usage by the participant(s). Frequently used codes interpretively reflect the mind set of participants. In this case, looking at code frequencies, Indian millennials' mind set can be interpretively understood. Innovative/creative idea of a millennial to start a venture which can bring solution to some existing social problems and help the entrepreneur give back to the society 
is something that can be viewed as "altruistic" need. This has obviously more importance than the commercial profit motive.

\subsection{Code and Code Categories: Plotting}

Using R-QDA Package (Source: CRAN) a thematic mapping of codes and respective categories on which they load was drawn. Three different layouts e.g. Fruchterman-Reingold; Kamada-Kawai and Reingold-Tilford Layouts are presented in Figures 1(a)-(c).

Three of the layouts show that thematically few codes load on multiple categories (Inter-coder agreement not checked). "Achievement”, “Ambition”, "Daringness" load on both "Personality" as well as on "Personal Goal" categories. Similarly, "Initiation" \& "Achievement" load on "Societal Focus" category too. This means that few of the personality dimensions of millennials have a natural inclination towards societal causes and help them plan initiatives to solve them. In this analysis, the complete text of male and female millennial participants is taken together to have an understanding of overall phenomenon of "entrepreneurship".

\subsection{Text Analytics}

This analytics procedure was done using R/R Studio and few necessary packages e.g. "tm", "wordcloud", "stopwords", "stringr" etc. Wordcloud analytics visually represents text segments/words more frequently used during the conversation.

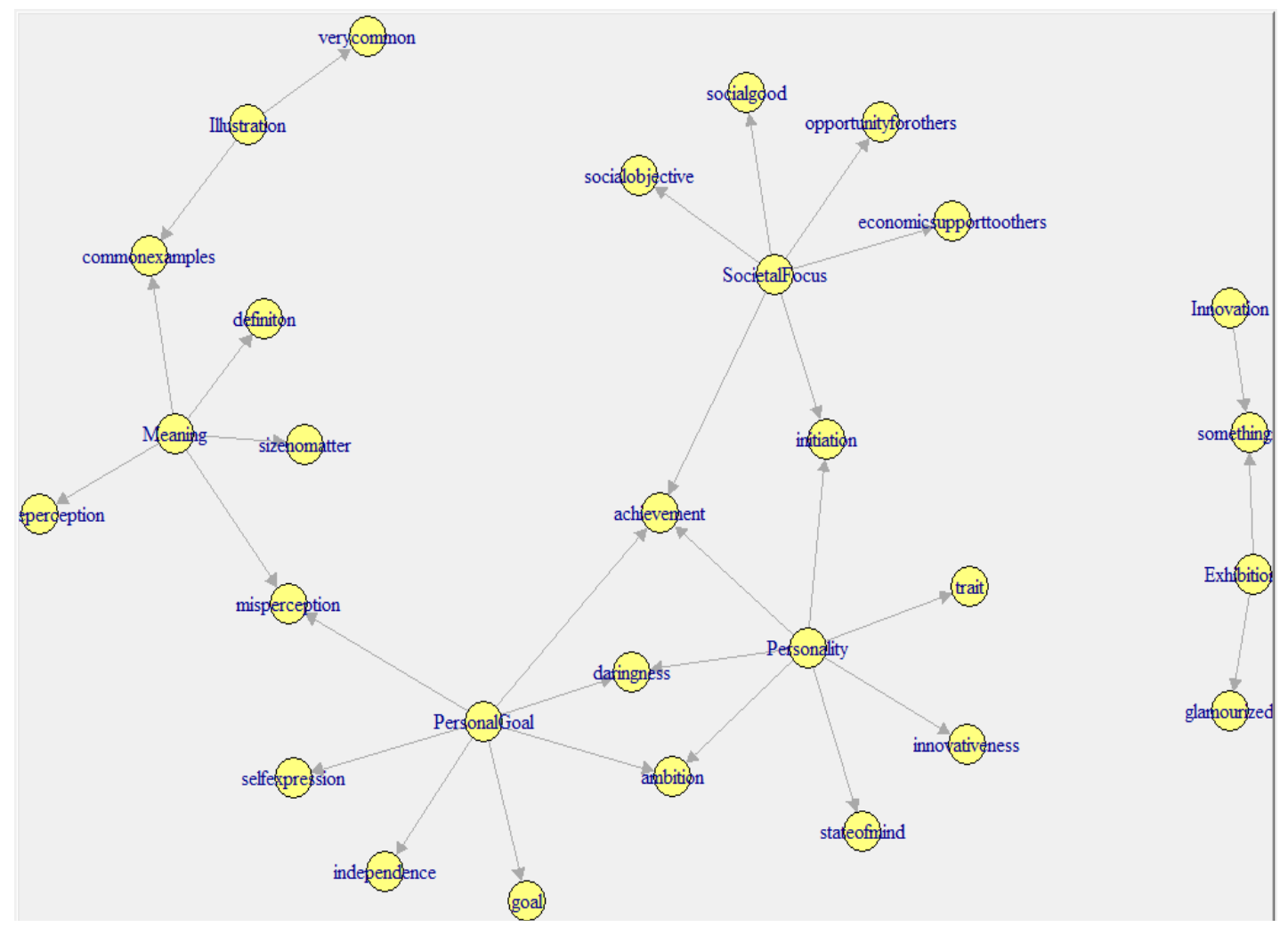

(a) 


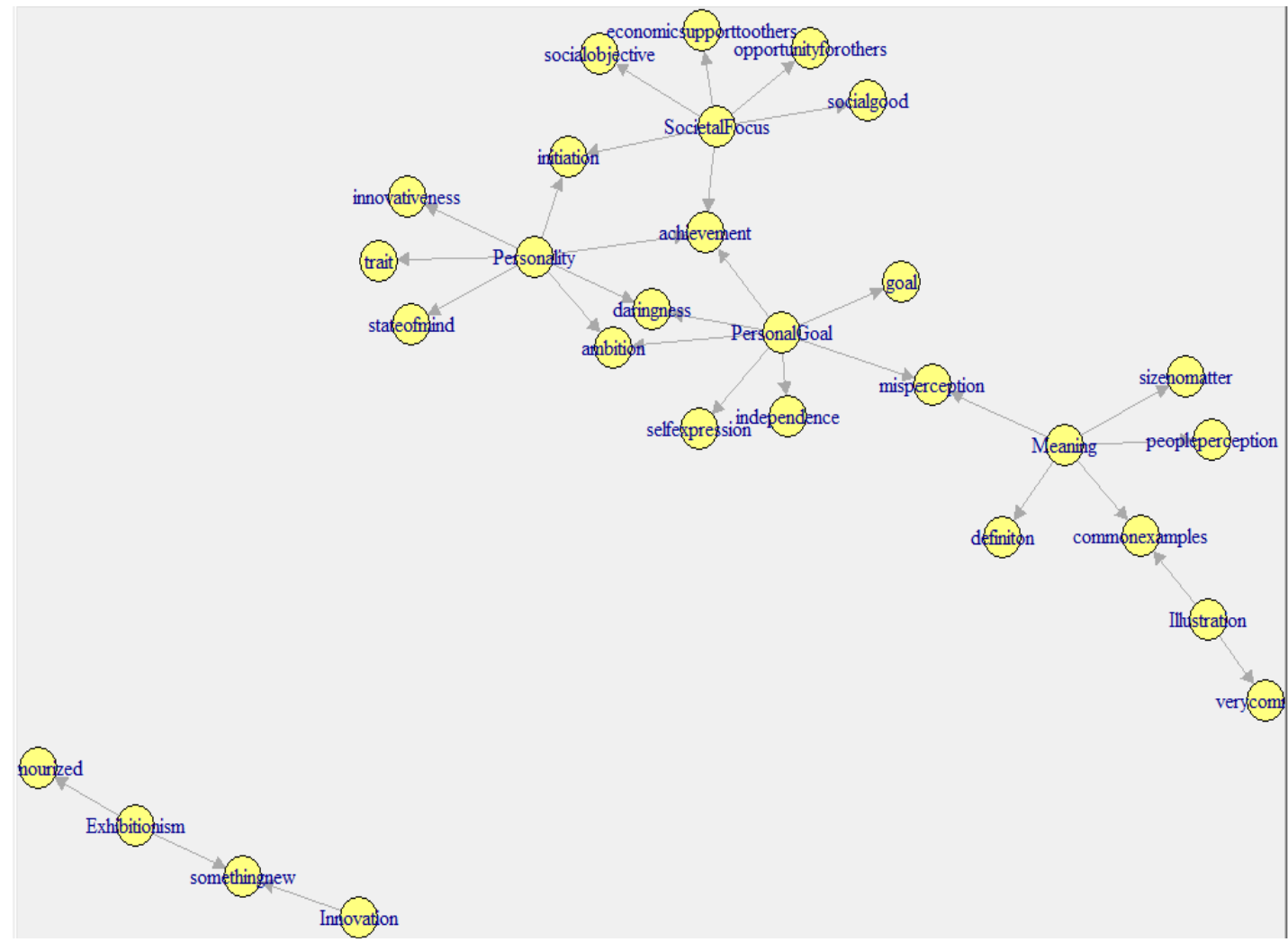

(b)
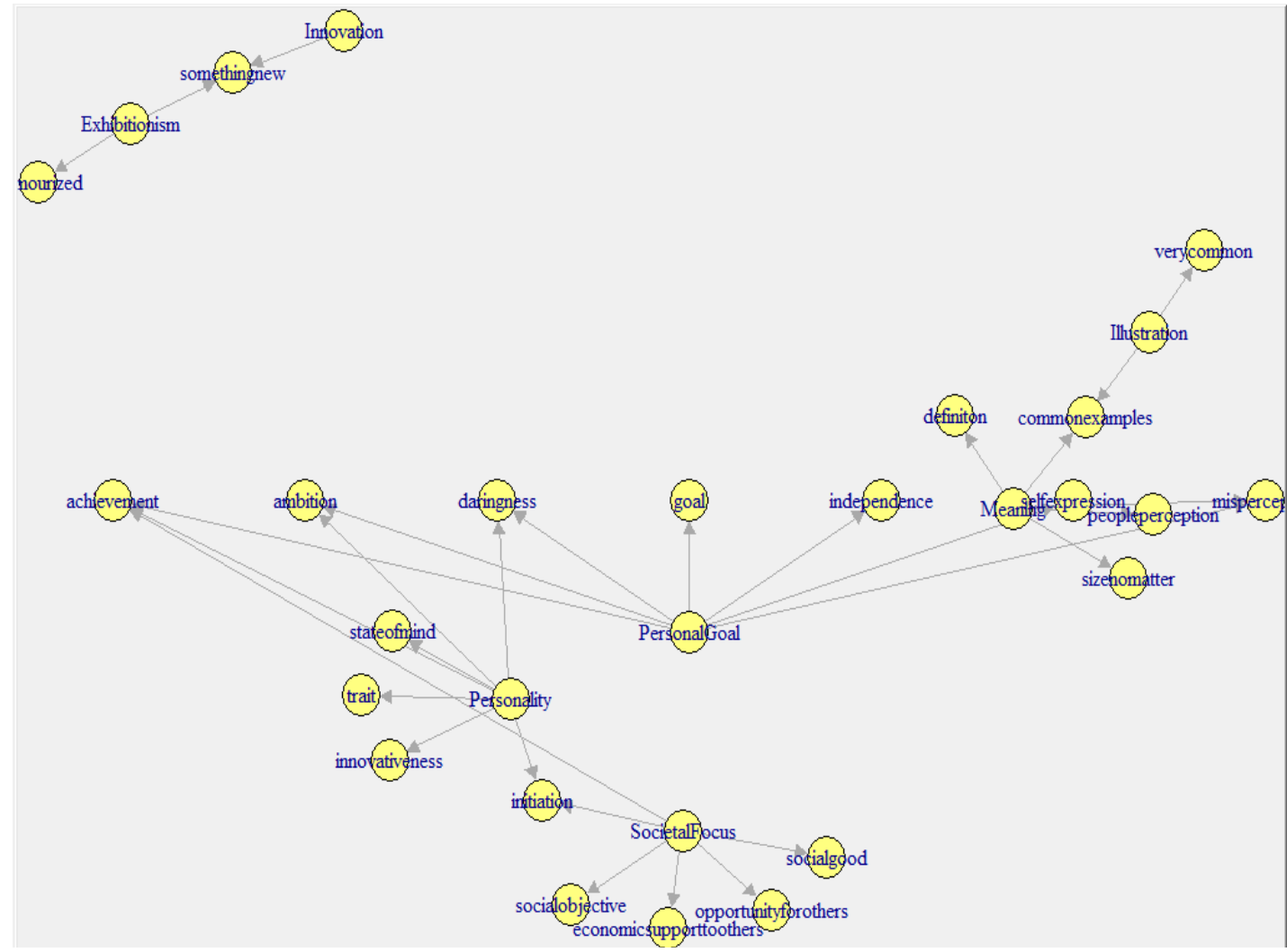

(c)

Figure 1. (a) Fruchterman-Reingold Layout; (b) Kamada-Kawai Layout; (c) Reingold-Tilford Layout. 
The assumption is the more in the frequency of usage more in the emphasis given by the participant. This can also give a sense whether the words frequently used have negative or positive connotation to adjudge the aggregate or average sentiment of all participants taken together. For wordcloud, a corpus of words is generated from the complete transcript. Various textual cleaning techniques are used in R-platform such as removal/changes of upper cases, punctuation, blank spaces, single lettered words (e.g. a, an, 's etc.), stopwords in English contributing little to the analytics (e.g. am, are, the etc.). In this analysis, a comparison is drawn between male and female millennials interested to become an entrepreneur in future.

\section{(a) Wordcloud}

The above visualization can be interpreted in varieties of ways. Both male \& female millennials are seen to like the idea of entrepreneurship. The females are seen to be vocal about "can do" attitude of theirs when compared to males. They vouch for innovativeness of idea behind. The people or society element in the discussion seems to be of equal importance to both the gender groups indicating their societal orientation and focus. Family background and support though in both the cases looks an area of discussion, but does not seem to be very prominent.

(b) Sentiment Analysis

Gender wise number of participants has some difference. However, the opportunity
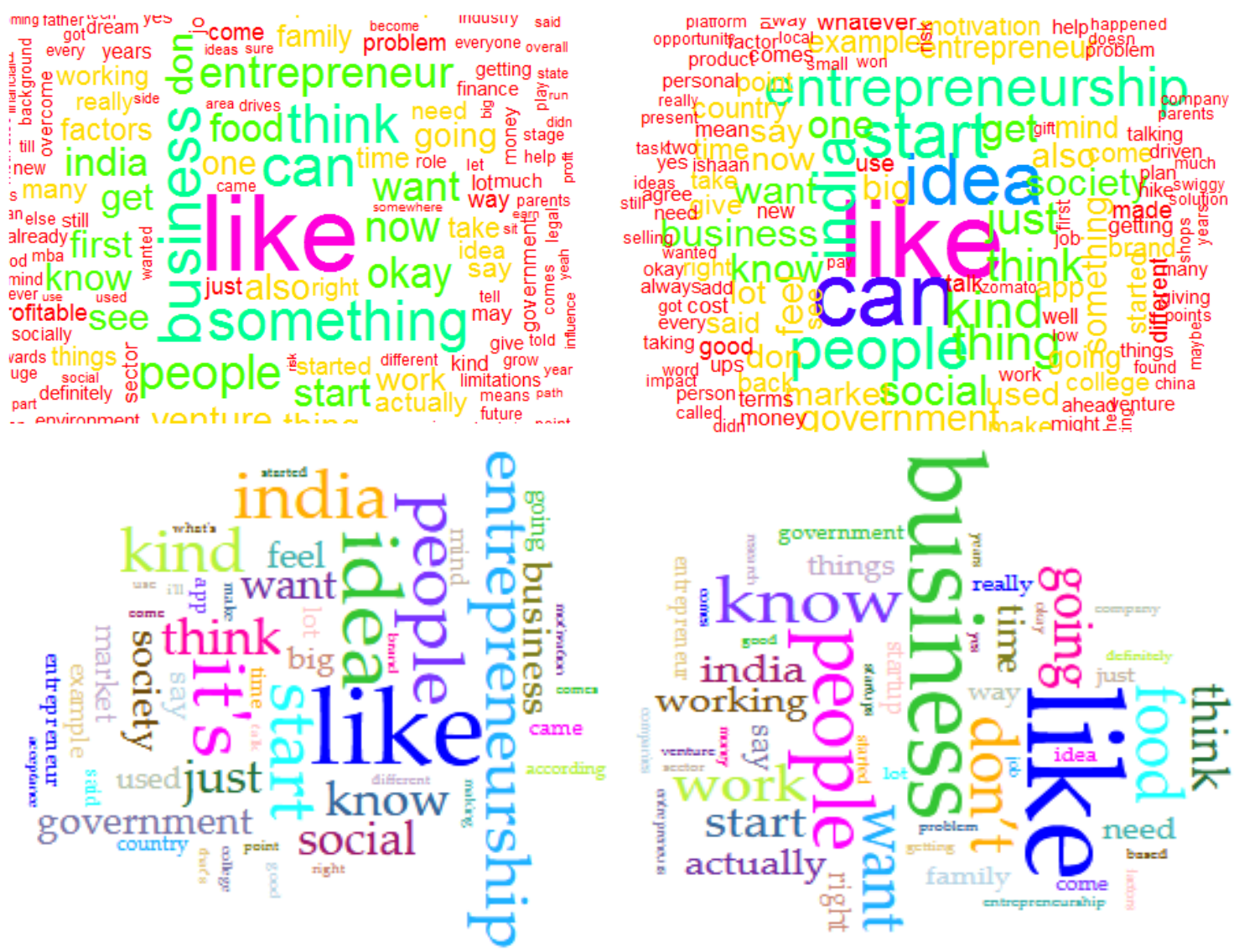

Figure 2. Males vs Females. 1) Using R-QDA ( ${ }^{\text {st }}$ row); 2) Using free tool http://www.voyant-tools.org/ (2 ${ }^{\text {nd }}$ row). 
obtained to speak was almost comparable in both cases. There may be some limitations in case of males attending FGD due to inhibition in a group setting. But the underlying assumption is that a young Indian millennial entrepreneur is expressive. Using sentiment analyzer in $\mathrm{R}$ platform separately for two gender groups, the corpus created from the respective document was compared against positive and negative words in English (Appendix 1: Source: http://www.ptrckprry.com/) for finding respective frequencies. Figure 2 and Table 3 show a gender wise comparison of these words.

Table 3. Sentiment analysis-gender wise distribution.

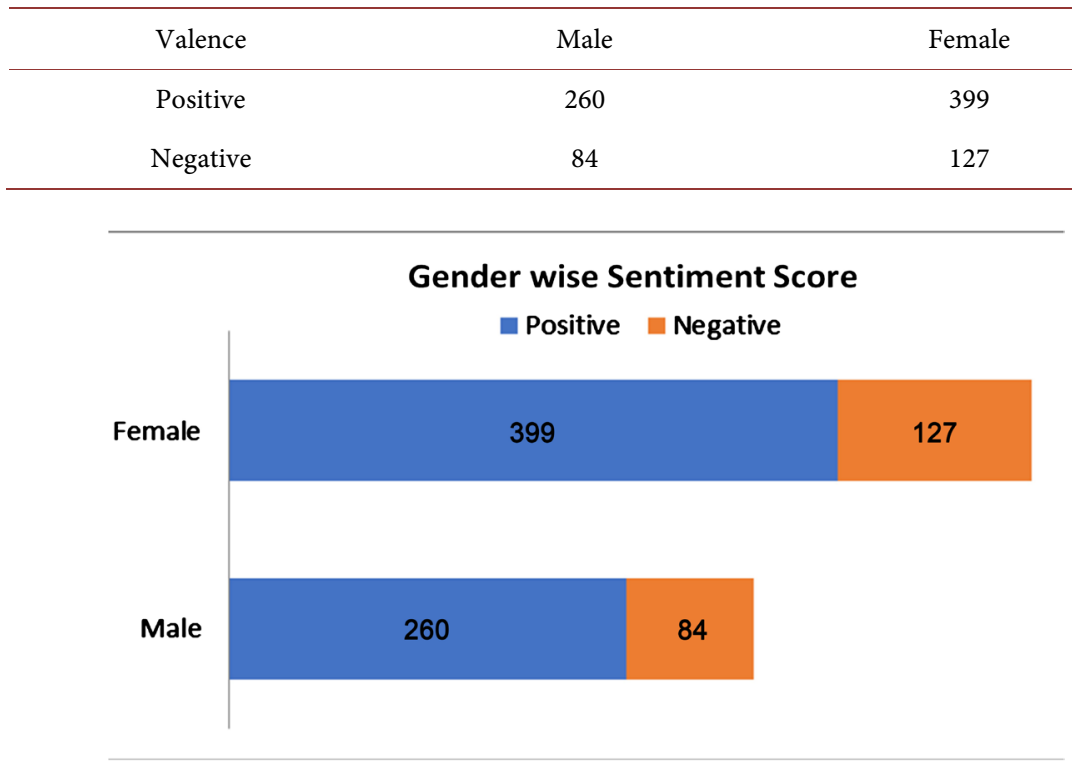

Net sentiment score for female millennials is $399-127=272$; and for males it is $260-84=176$. It can be interpreted that females show more positive sentiments compared to males when it is their perception and attitude towards entrepreneurship. This seems to be a departure when compared to the situation as it was few decades back. Increasing gender equality in Indian society is visible which is good in general.

\section{Conclusion}

The motivation of millennials to explore social sphere for business opportunity is noticed in this study, as they seek opportunities to address social issues by bringing out solutions to existing social problems. Social entrepreneurship with altruistic need among Indian millennial is evident. An "altruistic" need can be viewed as motivation to find a creative solution to a well-defined ongoing social problem given back to the society. This was obviously more important than the commercial profit motive. All the units of analyses are taken together for the male and female millennial participants, it is seen that the people or society element in the discussion seems to be of equal importance to both the gender groups indicating their societal orientation and focus. Family background and 
support in both the cases looks an area of discussion, but does not seem to be very prominent. This seems to be a departure when compared to the situation as was there few decades back. An increase in gender equality in Indian society is visible here as a cause of this, which is good in general. This study demonstrates procedural approach for conducting an interpretivist qualitative research on a smaller set of participants with social constructionism of Indian milieu comprising millennials. The vigor and vibrancy of youth in the country and their positive attitude towards social well-being of fellow country-men is highly appreciable in the findings. All start-up that has been undertaken or about to be undertaken by millennials may not have pure profit motive. Moreover profit earning is seen by a by-product in most of the conversations that have been studied with a primary focus being active in innovatively solving societal issues.

\section{Conflicts of Interest}

The authors declare no conflicts of interest regarding the publication of this paper.

\section{References}

[1] Myers, D.G. (2008) Religion and Human Flourishing. In: Eid, M. and Larsen, R., Eds., The Science of Subjective Well-Being, Guilford, New York, 323-346.

[2] Pizam, A. and Mansfeld, Y. (2009) Consumer Behaviour in Travel and Tourism. Taylor and Francis Group, London.

[3] Bolton, B. and Thompson, J. (2000) Entrepreneurs, Talent, Temperament, Technique. Butterworth Heinemann, Oxford.

[4] Bolton, B. and Thompson, J. (2002) The Entrepreneur in Focus: Achieve Your Potential. Thomson Learning, London.

[5] Gürol, Y. and Atsan, N. (2006) Entrepreneurial Characteristics amongst University Students: Some Insights for Entrepreneurship Education and Training in Turkey. Education + Training, 48, 25-38. https://doi.org/10.1108/00400910610645716

[6] Rohrbach, J. (1998) Helping Entrepreneurs Navigate during the Start-Up and Funding Process. Mentor Networks USA.

[7] Kar, S.K. and Samantarai, M. (2011) Narrative Research on "Bothra": An Indian Family Firm. Society and Business Review, 6, 131-148. https://doi.org/10.1108/17465681111143957

[8] Fraboni, M. and Saltstone, R. (1990) First and Second Generation Entrepreneur Typologies: Dimensions of Personality. Journal of Social Behavior and Personality, 5, 105-113.

[9] Chaudhary, R. (2017) Demographic Factors, Personality and Entrepreneurial Inclination: A Study among Indian University Students. Education + Training, 59, 171-187. https://doi.org/10.1108/ET-02-2016-0024

[10] Thompson, J.L. and Downing, R. (2007) The Entrepreneur Enabler: Identifying and Supporting Those with Potential. Journal of Small Business and Enterprise Development, 14, 528-544. https://doi.org/10.1108/14626000710773592

[11] Smith, J.M. (1973) A Quick Measure of Achievement Motivation. British Journal of Social and Clinical Psychology, 12, 137-143.

https://doi.org/10.1111/j.2044-8260.1973.tb00859.x 
[12] Warr, P., et al. (1979) Scales for the Measurement of Some Work Attitudes and Aspects of Psychological Wellbeing. Journal of Occupational Psychology, 52, 129-148. https://doi.org/10.1111/j.2044-8325.1979.tb00448.x

[13] Budner, S. (1962) Intolerance of Ambiguity as a Personality Variable. Journal of Personality, 30, 29-50. https://doi.org/10.1111/j.1467-6494.1962.tb02303.x

[14] Brockhaus, R.H. (1980) Psychological and Environmental Factors Which Distinguish the Successful from the Unsuccessful Entrepreneur: A Longitudinal Study. Academy of Management Proceedings, 1980, 368-372. https://doi.org/10.5465/ambpp.1980.4977943

[15] Littunen, H. (2000) Entrepreneurship and the Characteristics of the Entrepreneurial Personality. International Journal of Entrepreneurial Behavior \& Research, 6, 295-310. https://doi.org/10.1108/13552550010362741

[16] Green, et al. (1996) The Russian Entrepreneur: A Study of Psychological Characteristics. International Journal of Entrepreneurial Behavior \& Research, 2, 49-58. https://doi.org/10.1108/13552559610110718

[17] Cassidy, T. and Lynn, R. (1989) A Multifactorial Approach to Achievement Motivation. Journal of Occupational Psychology, 62, 301-312. https://doi.org/10.1037/t07252-000

[18] Gibb, A. and Ritchie, J. (1981) Influences on Entrepreneurship: A Study over Time. Proceedings of the UK Small Business Research Conference, 20-21 November 1981, Polytechnic of Central London, London.

[19] Winfield, I. (1984) People in Business. Heinemann, London.

[20] Miller and Friesen (1982) Innovation in Conservative and Entrepreneurial Firms: Two Models of Strategic Momentum. Strategic Management Journal, 3, 1-25. https://doi.org/10.1002/smj.4250030102

[21] De Witt, G. and Van Winden, F. (1989) An Empirical Analysis of Self-Employment in the Netherlands. Small Business Economics, 1, 263-272. https://doi.org/10.1007/BF00393805

[22] Taylor, M.P. (1996) Earnings, Independence or Unemployment: Why Become Self-Employed? Oxford Bulletin of Economics and Statistics, 58, 253-266. https://doi.org/10.1111/j.1468-0084.1996.mp58002003.x

[23] Crant, J.M. (1996) The Proactive Personality Scale as a Predictor for Entrepreneurial Intention. Journal of Small Business Management, 34, 42-49.

[24] Dolton, P.J. and Makepeace, G.H. (1990) Self-Employment among Graduates. Bulletin of Economic Research, 42, 35-54. https://doi.org/10.1111/j.1467-8586.1990.tb00290.x

[25] Evans, D. and Leighton, L.S. (1989) Some Empirical Aspects of Entrepreneurship. American Economic Review, 79, 519-535. https://doi.org/10.1007/978-94-015-7854-7_6

[26] Fagenson, E.A. (1993) Women and Work: A Research and Policy Series, 4. Women in Management: Trends, Issues, and Challenges in Managerial Diversity. Sage Publications, Inc., Thousand Oaks.

[27] McClelland, D.C. (1987) Human Motivation. Cambridge University Press, New York. https://psycnet.apa.org/record/1988-97516-000

[28] Van Stel, A., Storey, D.J. and Thurik, A.R. (2007) The Effect of Business Regulations on Nascent and Young Business Entrepreneurship. Small Business Economics, 28, 171-186. https://doi.org/10.1007/s11187-006-9014-1

[29] Baporikar, N. (2014) Youth Entrepreneurship in Indian Scenario. International Jour- 
nal of Asian Business and Information Management, 5, 74-84. https://doi.org/10.4018/ijabim.2014040106

[30] Coviello, N. (2014) How to Publish Qualitative Entrepreneurship Research in Top Journals. In: Fayolle, A. and Wrightm, M., Eds., How to Get Published in the Best Entrepreneurship Journals. A Guide to Steer Your Academic Career, Edward Elgar, Cheltenham, 167-182. https://doi.org/10.4337/9781782540625.00016

[31] Hunt, S.D. (1991) Positivism and Paradigm Dominance in Consumer Research: Toward Critical Pluralism and Rapprochement. Journal of Consumer Research, 18, 32-44. https://doi.org/10.1086/209238

[32] Goulding, C. (2005) Grounded Theory, Ethnography and Phenomenology. European Journal of Marketing, 39, 294-308. https://doi.org/10.1108/03090560510581782

[33] Langley, A. and Abdallah, C. (2011) Templates and Turns in Qualitative Studies of Strategy and Management. In: Berg, D.D. and Ketchen, D.J., Eds., Building Methodological Bridges, Research Methodology in Strategy and Management, Emerald Group Publishing, Bingley, 201-235.

https://doi.org/10.1108/S1479-8387(2011)0000006007

[34] Myers, M.D. (2008) Qualitative Research in Business \& Management. Sage Publications, Thousand Oaks.

https://research-methodology.net/research-philosophy/interpretivism/\#_ftn1

[35] Hunt, S.D. (1994) On Rethinking Marketing: Our Discipline, Our Practice, Our Methods. European Journal of Marketing, 28, 13-25.

https://doi.org/10.1108/03090569410057263

[36] Peters, et al. (2013) Constructivism and Critical Realism as Alternative Approaches to the Study of Business Networks: Convergences and Divergences in Theory and in Research Practice. Industrial Marketing Management, 42, 336-346. https://doi.org/10.1016/j.indmarman.2013.02.003

[37] Easton, G. (2010) Critical Realism in Case Study Research. Industrial Marketing Management, 39, 118-128. https://doi.org/10.1016/j.indmarman.2008.06.004

[38] Sobh, R. and Perry, C. (2006) Research Design and Data Analysis in Realism Research. European Journal of Marketing, 40, 1194-1209. https://doi.org/10.1108/03090560610702777

[39] Tsang, E.W. (2014) Case Studies and Generalization in Information Systems Research: A Critical Realist Perspective. The Journal of Strategic Information Systems, 23, 174-186. https://doi.org/10.1016/j.jsis.2013.09.002

[40] Huang, R.G. (2014) RQDA: R-Based Qualitative Data Analysis: R Package Version 0.2-7. http://rqda.r-forge.r-project.org

[41] Bruner (1990) Acts of Meaning. Harvard University Press, Cambridge, London. 


\section{Appendix 1. Supplementary Note Shared with Participants for Information Prior to FGD}

"WELCOME TO THE FGD ... We expect you to read the following and come with some homework on the theme"

Entrepreneurship may mean different things/activities to different persons, as different people have different aspirations/motivations.

- For some, it is lifestyle-oriented, e.g. People making a living out of sea sports may target surfers and scuba divers, few may just offer training to the sports enthusiasts, few may even partner with the Govt. to be life guards.

- Few may understand entrepreneurship as small businesses, usually family owned and managed. They join other members in family to continue the legacy. The modern generation may scale up the business through branching out at multiple places or expanding volume and market reach.

- Some believe in chasing a scalable idea being incubated in innovation ecosystem. It may outsize returns, though attracts all the risk capital.

- Some mean it as something that is designed to be quickly sold, flipped and to build a billion dollar business, often called "serial entrepreneurs"

- Sometimes even large companies foster innovation and spin off a venture to exploit changes in customer tastes, new technologies, legislation, new competitors etc.

- Social startup is categories where entrepreneurs help solve social problems. Individuals work to create technology-enabled solutions for problems like water management, waste disposal, education, and job creation. Though based on social issues, it can still make operating profit. The world is made a better place to live by them.

Startup India is a flagship initiative of the Government of India, to build a strong eco-system for nurturing innovation and Startups in the country. GoI's action Plan is based on: Simplification and Handholding; Funding Support and Incentives, and Industry-Academia Partnership and Incubation.

Startup entity registration: In India a startup can be registered as: Private Limited Company; Limited Liability Partnership; or Registered Partnership. The entities shall cease to be a "Startup" on completion of seven years from the date of its incorporation/registration; however, in biotechnology sector, the period is up to ten years from the date of incorporation, or at the end of the financial year in which its turnover exceeds Rs 25 crore.

Important Factors: Host of factors that seem important for a budding entrepreneur are: Market Size, growth, price pressure, stage of innovation idea, effects of business cycles, supplier \& business partner concentration, existing \& potential competitors, ease of entry to \& exit from business, scope of merger \& acquisition, substitution effect, pace of change in industry, innovation \& scalability, technological complexity \& upgradability, product diversity \& differentiability, intellectual rights protection, profitability \& breakeven, cost of capital, meta market synergies, govt. subsidies, social \& environmental trends, regulatory compliance, etc. India as a country can be compared with any other country in terms of all factors mentioned above. Thus a budding intelligent entrepreneur assesses such factors on their importance to his/her entrepreneurial plans and the existing strength of these factors in India.

FGD: We have made a shortlisted homogeneous group of 8 - 10 members for a moderated open ended discussion. This discuss would continue for about 60 to 90 minutes. Remember it is NOT debate, or conflict resolution/problem solving session. You are ENCOURAGED to give your well thought neutral opinion. Please maintain a professional and cordial gesture to fellow-participant and make your communication clear, precise and substantive without forming any sub-group within the group. With your permission the process will be RECORDED with an assurance of CONFIDENTIALITY. 


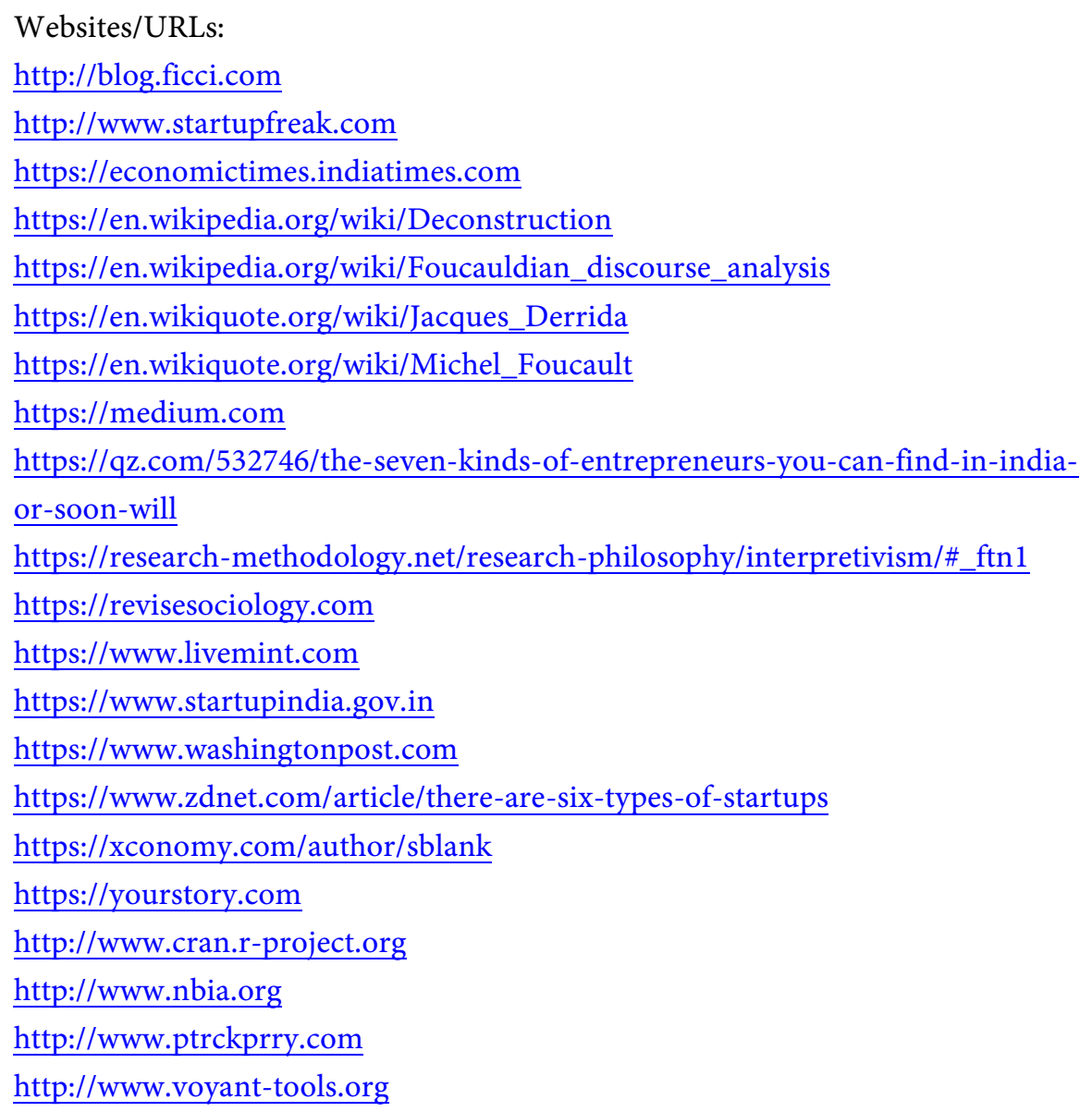

\section{Appendix 2. Questions to Moderate FGD \& Conduct Depth Interview}

(a) FGD Moderation

1. What is there in you that drives/motivates you to go for entrepreneurship?

2. What all personal weaknesses/limitations you think you should try to overcome for its success?

3. What all external factors you think you should consider? Does your family background influence your decision?

4. What kind of venture you are into/planning to start, and why so? How do you assess opportunity?

5. Comment on the overall climate in India towards entrepreneurship culture. What is still missing?

6. Which kinds of venture seem more profitable in India these days?

7. Does an entrepreneur have to be socially/environmentally concerned?

8 . How long have you been continuing your current venture, if any? What challenges do you face?

9. When are you planning to start your venture? Are you not looking for campus placement? (b) Depth Interview Schedule

1. What basically drives you or motivates you for being an entrepreneur?

2. Anything that stops you from going closer to your dream of being an entrepreneur?

3. How can you overcome your personal limitations to be a successful entrepreneur?

4. Does your family background influence your decision of becoming an entrepreneur or you had this vision of being an entrepreneur in your mind from the starting or they play a role in this journey?

5. What kind of venture are you planning to start? Any specific reason why you want to go with this venture?

6. How do you assess the opportunity at present in India?

7. What would you follow, profitability or your passion in terms of entrepreneurship?

8. Do you think an entrepreneur should be socially or environmentally responsible?

9. Will campus placement be your immediate goal or directly being an entrepreneur? 
Appendix 3. Sample Characteristics: FGD (Males, $\mathbf{N}=9$ )

\begin{tabular}{|c|c|c|c|c|c|c|c|}
\hline S.No. & Age (yrs) & State & Zone & $\begin{array}{l}\text { Work Experience } \\
\text { (Months) }\end{array}$ & $\begin{array}{l}\text { Family Income } \\
\text { (Lakh INR) }\end{array}$ & $\begin{array}{c}\text { Family } \\
\text { Business }\end{array}$ & $\begin{array}{l}\text { Educational } \\
\text { Background }\end{array}$ \\
\hline M1 & 27 & $\mathrm{DL}$ & North & 48 & 5.5 & No & Technical \\
\hline M2 & 23 & WB & East & 0 & 6 & Yes & Nontechnical \\
\hline M3 & 25 & $\mathrm{~PB}$ & North & 16 & 10 & No & Nontechnical \\
\hline M4 & 22 & UP & North & 0 & 12 & Yes & Nontechnical \\
\hline M5 & 23 & $\mathrm{HR}$ & North & 17 & 60 & Yes & Nontechnical \\
\hline M6 & 24 & AS & East & 0 & 15 & No & Technical \\
\hline M7 & 26 & OD & East & 30 & 10 & Yes & Nontechnical \\
\hline M8 & 22 & GJ & West & 0 & 12 & No & Nontechnical \\
\hline M9 & 23 & MG & East & 0 & 5 & No & Nontechnical \\
\hline \multicolumn{8}{|c|}{ Sample Characteristics: Depth Interview (Females, $N=7$ ) } \\
\hline M1 & 21 & CG & Central & 0 & 25 & Yes & Nontechnical \\
\hline M2 & 24 & $\mathrm{DL}$ & North & 0 & 25 & No & Technical \\
\hline M3 & 21 & TS & South & 0 & 6.5 & No & Technical \\
\hline M4 & 22 & MH & West & 0 & 13 & Yes & Nontechnical \\
\hline M5 & 21 & KA & South & 12 & 8.5 & No & Nontechnical \\
\hline M6 & 22 & $\mathrm{~PB}$ & North & 0 & 10 & Yes & Nontechnical \\
\hline M7 & 21 & TS & South & 0 & 7.5 & Yes & Nontechnical \\
\hline
\end{tabular}

